\title{
Treatment efficacy in a soman-poisoned guinea pig model: added value of physostigmine?
}

\author{
Marloes J. A. Joosen · August B. Smit • \\ Herman P. M. van Helden
}

Received: 21 February 2010/ Accepted: 15 June 2010/Published online: 15 September 2010

(C) The Author(s) 2010. This article is published with open access at Springerlink.com

\begin{abstract}
Current treatment of organophosphate poisoning is insufficient, and survivors may suffer from long-lasting adverse effects, such as cognitive deficits and sleep-wake disturbances. In the present study, we aimed at developing a guinea pig model to investigate the benefits of immediate and delayed stand-alone therapy on the development of clinical signs, EEG, heart rate, respiration and AChE activity in blood and brain after soman poisoning. The model allowed the determination of the therapeutic effects at the short-term of obidoxime, atropine and physostigmine. Obidoxime exerted the highest therapeutic efficacy at administration of the lowest dose $(3.1 \mathrm{mg} / \mathrm{kg}$ i.m.), whereas two higher doses ( 9 and $18 \mathrm{mg} / \mathrm{kg}$ ) were less effective on most parameters. Addition of atropine at 0.03 and $3 \mathrm{mg} / \mathrm{kg}$ (i.m.) to the treatment did not improve the therapeutic effects of obidoxime alone. Physostigmine $(0.8 \mathrm{mg} / \mathrm{kg} \mathrm{im})$ at $1 \mathrm{~min}$ after poisoning increased mortality. Two lower doses $(0.1$ and $0.3 \mathrm{mg} / \mathrm{kg}$ i.m.) showed improvements on all parameters but respiration. The middle dose was most effective in preventing seizure development and therefore assessed as the most efficacious dose. Combined treatment of obidoxime and physostigmine shortened the duration of seizures, if present, from up to $80 \mathrm{~min}$ to $\sim 10-15 \mathrm{~min}$. In practice, treatment will be employed when toxic signs appear, with the presence of high levels of AChE inhibition in both blood and brain. Administration of physostigmine at that moment showed to
\end{abstract}

M. J. A. Joosen $(\bowtie)$ · H. P. M. van Helden TNO Defence, Security and Safety, BU CBRN Protection, Lange Kleiweg 137, 2288 GJ Rijswijk, The Netherlands e-mail: marloes.joosen@tno.nl

A. B. Smit

Centre for Neurogenomics and Cognitive Research, VU University, Amsterdam, The Netherlands be redundant or even harmful. Therefore, treatment of OP poisoning with a carbamate, such as physostigmine, should be carefully re-evaluated.

Keywords Soman Physostigmine - Organophosphate · Seizures · Obidoxime

\section{Introduction}

Organophosphates (OPs) are highly toxic chemicals, which mainly exert their toxicity by irreversible inhibition of acetylcholinesterase (AChE) and the consequent excessive and deleterious buildup of acetylcholine (Maxwell et al. 2006). Nerve agents are the most toxic OPs and might be used in military conflicts or in terrorist attacks, such as those in the Tokyo subway station in 1995 (Suzuki et al. 1995). The buildup of acetylcholine (ACh) following OP exposure in central and peripheral synapses leads to typical cholinergic signs due to overstimulation of nicotinergic and muscarinergic synapses. This overstimulation evolves into hypersecretions, failure of neuromuscular transmission, seizures, convulsions and eventually death due to respiratory failure (Shih and McDonough 1997; van Helden and Bueters 1999). In preclinical studies, the currently available treatment regimens appeared to be ineffective in preventing this, giving way to seizures that might induce brain damage and concomitant deficits in cognition and attention even when they are short-lasting (Joosen et al. 2009; Raveh et al. 2003).

Treatment is generally aimed at three targets. The first one, achieved by oxime treatment, is breaking the covalent bond of the OP from the serine residue in the active site of AChE. However, no broad-spectrum oximes are available to manage the chemistry of all nerve agents (Aas 2003; 
Maxwell et al. 2008). Moreover, none of the oximes are capable to reactivate inhibited and "aged" AChE, i.e. when the alkyl tail of the OP molecule has gone, thereby rendering the remaining bond virtually irreversible (Berman and Decker 1986). The second target of treatment is directed towards blocking muscarinic overstimulation using compounds such as atropine sulphate. Although rather effective at very high doses, atropine rapidly looses efficacy when administered at low doses or after development of full-blown seizures (Shih and McDonough 2000). The final treatment is aimed at terminating seizures by benzodiazepines in order to prevent brain injury. Recent research suggested that seizures lasting no longer than $10 \mathrm{~min}$ did not induce visible brain damage but rather inhibited neurogenesis resulting in impaired cognitive performance (Joosen et al. 2009). These and other findings show the need to advance understanding of the toxic as well as the antidotal mechanisms in order to obtain more effective medical countermeasures.

Therefore, the present study was aimed at investigating several features of OP poisoning and treatment. The nerve agent soman was chosen as a model compound because it is expected to have the highest risk of inducing brain damage (McDonough et al. 1999, 2000), and after binding to $\mathrm{AChE}$, it ages very rapidly. This makes poisoning with soman less prone to successful treatment with any of the existing oximes, such as 2-PAM, obidoxime and HI-6. It is known that preserving or restoring AChE pools is one of the most efficacious treatments in case of nerve agent poisoning and most effective when employed very rapidly after poisoning. Although the reactivating capacity of obidoxime towards soman-inhibited AChE activity is known to be very low, this oxime was used in the present experiments for two reasons. The first reason was purely practical in that obidoxime is currently in use as an autoinjector compound. Second, the use of obidoxime would enable the identification of other targets for obidoxime efficacy than $\mathrm{AChE}$ reactivation alone (Maxwell et al. 2006).

Recently, post-poisoning treatment with carbamates has been proposed. For example, physostigmine, previously shown to be highly effective as pretreatment against OP poisoning, was effective against 5 LD50 soman in guinea pigs, administered 1 min post-poisoning in combination with scopolamine and HI-6 (Wetherell et al. 2006, 2007). Also galantamine showed efficacy when administered shortly after poisoning with VX or soman (Albuquerque et al. 2006; Hilmas et al. 2009).

In the present study, a soman-poisoned guinea pig model was developed to enable the investigation of the impact of different doses of soman and subsequent relief of toxic signs by different treatment protocols. The guinea pig is the most widely accepted non-primate model for predicting treatment efficacy for nerve agent poisoning in primate species (Dirnhuber et al. 1979; Gordon et al. 1978). Our approach enabled online monitoring of vital physiological signs and off-line determination of biochemistry in terms of AChE and butyrylcholinesterase (BuChE) activity. Both physiology and biochemistry were investigated for being suitable parameters predictive for clinical outcome. The therapeutic efficacy of several treatment combinations of obidoxime, atropine sulphate and physostigmine, administered at 1 or $10 \mathrm{~min}$ following poisoning, was tested. The research was focused on the identification of the contributing role of physostigmine in the treatment.

\section{Methods}

Animals

Male Dunkin Hartley guinea pigs (Crl:HA) obtained from Charles River (Maastricht, The Netherlands) were used in the present study. Prior to the experiments, they were housed with two animals per cage and allowed to get accustomed to standard conditions for 1 week. Room temperature was kept at $19-22^{\circ} \mathrm{C}$, and relative humidity was maintained at 55-65\%, and lights were on from 7 am to $7 \mathrm{pm}$. Acidified water and standard guinea pig chow (Teklad global diet 2040, Harlan, Horst, The Netherlands) were available ad libitum. The experiments described received prior approval from the TNO Animal Ethical Committee.

\section{Chemicals}

Hypnorm $^{\circledR}$ (fentanyl/fluanisone) was purchased from Janssen Pharmaceutica (Beerse, Belgium), and Dormicum $^{\circledR}$ (midazolam) was delivered by Roche Nederland BV (Mijdrecht, The Netherlands). Soman (O-Pinacolyl methylphosphonofluoridate) was obtained from the stocks of TNO Defence, Security and Safety and of purity $\geq 98 \%$ (GC). The other chemicals used were of standard purity and purchased from renowned companies.

\section{Study design}

The design of the study is presented in Fig. 1. After obtaining baseline values of the indicated parameters for $30 \mathrm{~min}$, the guinea pigs were poisoned with soman $(30 ; 37$ or $44 \mu \mathrm{g} / \mathrm{kg}$ s.c.; corresponding to $\sim 1.2 ; 1.5$ and $1.824 \mathrm{~h}$ LD50, respectively, (Gordon and Leadbeater 1977), followed by i.m. treatment 1 or 10 min later. The experiment was divided in four parts: establishment of a model dose for soman; efficacy of conventional treatment by obidoxime and atropine; efficacy of physostigmine; and the 


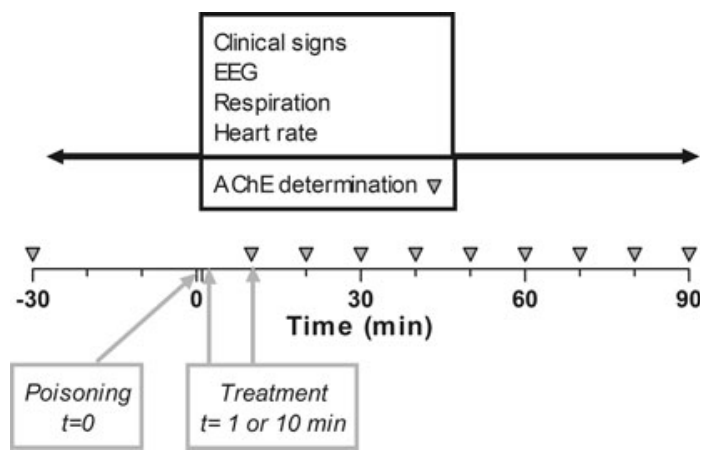

Fig. 1 Overview of the experimental design. Before and after poisoning, EEG, ECG, respiration and clinical signs were continuously monitored. Every 10 min after poisoning, blood was drawn from the ear vein to determine blood ChE activity

efficacy of postponed treatment (Table 1). A control group was injected with saline (s.c.) followed by an i.m. saline injection. At the indicated time points $(\nabla)$, blood samples were drawn from the ear vein to assess AChE activity. Following poisoning, the guinea pigs were observed for toxic cholinergic signs such as chewing, tremor, salivation and convulsions. Clear chewing movements involving the entire head were scored as chewing, often accompanied by extensive drooling (salivation) later on. Involuntary shaking of parts of the body or head was scored as tremor. Convulsions were defined as involuntary movements of the entire body, while the animal looks dissociated from its environment. At the end of the experiment, $90 \mathrm{~min}$ after poisoning, different brain parts (hippocampus, striatum and medulla oblongata) were isolated for AChE level determination.

\section{Surgical procedures}

Guinea pigs were anaesthetized with $6 \mathrm{ml} / \mathrm{kg}$ FFM-mix $(1.25 \mathrm{mg} / \mathrm{ml}$ midazolam, $2.5 \mathrm{mg} / \mathrm{ml}$ fluanisone, $0.079 \mathrm{mg} / \mathrm{ml}$ fentanyl citrate) via a single i.p. injection. Premedication with $0.05 \mathrm{mg} / \mathrm{kg}$ atropine sulphate (s.c.) was administered to prevent respiratory arrest. Two stainless steel screws (A8.0 and P1.2 $\mathrm{mm}$ relative to bregma and $1 \mathrm{~mm}$ from the sagittal suture) placed at the dura mater, fixed to a plug, served as EEG electrodes. To obtain an ECG signal, two leads sutured in the superficial muscles under the skin just

Table 1 Overview of experimental groups

\begin{tabular}{|c|c|c|c|c|c|c|c|c|c|c|c|}
\hline \multirow[t]{3}{*}{ Experiment } & \multirow{3}{*}{$\begin{array}{l}\text { Exposure } \\
\text { Soman } \\
(\mu \mathrm{g} / \mathrm{kg} \text { s.c.) }\end{array}$} & \multicolumn{4}{|l|}{ Treatment } & \multicolumn{6}{|c|}{ Signs } \\
\hline & & \multirow{2}{*}{$\begin{array}{l}\text { Obidoxime } \\
\text { (mg/kg i.m.) }\end{array}$} & \multirow{2}{*}{$\begin{array}{l}\text { Physostigmine } \\
\text { (mg/kg i.m.) }\end{array}$} & \multirow{2}{*}{$\begin{array}{l}\text { Atropine sulphate } \\
\text { (mg/kg i.m.) }\end{array}$} & \multirow{2}{*}{$\begin{array}{l}\text { Time of treatment } \\
\text { (min after soman) }\end{array}$} & \multicolumn{2}{|c|}{ Seizures } & \multicolumn{2}{|c|}{ Convulsions } & \multicolumn{2}{|c|}{ 90-min survival } \\
\hline & & & & & & $(n)$ & $\%$ & $(n)$ & $\%$ & $(n)$ & $\%$ \\
\hline \multirow[t]{4}{*}{ Model } & 0 & - & - & - & - & $0 / 4$ & 0 & $0 / 4$ & 0 & $4 / 4$ & 100 \\
\hline & 30 & - & - & - & 1 & $6 / 6$ & 100 & $6 / 6$ & 100 & $5 / 6$ & 83 \\
\hline & 37 & - & - & - & 1 & $6 / 6$ & 100 & $6 / 6$ & 100 & $3 / 6$ & 50 \\
\hline & 44 & - & - & - & 1 & $6 / 6$ & 100 & $6 / 6$ & 100 & $1 / 6$ & 17 \\
\hline \multirow[t]{7}{*}{ Conventional } & 30 & 3.1 & - & - & 1 & $4 / 6$ & 67 & $2 / 6$ & 33 & $6 / 6$ & 100 \\
\hline & 30 & 9 & - & - & 1 & $5 / 6$ & 83 & $4 / 6$ & 67 & $6 / 6$ & 100 \\
\hline & 30 & 18 & - & - & 1 & $5 / 6$ & 83 & $4 / 6$ & 67 & $6 / 6$ & 100 \\
\hline & 30 & - & - & 3 & 1 & $5 / 6$ & 83 & $2 / 6$ & 33 & $6 / 6$ & 100 \\
\hline & 30 & 3.1 & - & 0.03 & 1 & $5 / 5$ & 100 & $4 / 5$ & 80 & $5 / 5$ & 100 \\
\hline & 30 & 3.1 & - & 3 & 1 & $4 / 5$ & 80 & $1 / 5$ & 20 & $4 / 5$ & 80 \\
\hline & 44 & 3.1 & - & 3 & 1 & $6 / 6$ & 100 & $6 / 6$ & 100 & $5 / 6$ & 83 \\
\hline \multirow[t]{7}{*}{ Physostigmine } & 30 & - & 0.1 & - & 1 & $4 / 4$ & 100 & $1 / 4$ & 25 & $4 / 4$ & 100 \\
\hline & 30 & - & 0.3 & - & 1 & $2 / 6$ & 33 & $2 / 6$ & 33 & $6 / 6$ & 100 \\
\hline & 30 & - & 0.8 & - & 1 & $1 / 2$ & 50 & $2 / 2$ & 100 & $0 / 2$ & 0 \\
\hline & 30 & 3.1 & 0.1 & - & 1 & $3 / 5$ & 60 & $1 / 5$ & 20 & $5 / 5$ & 100 \\
\hline & 30 & 3.1 & 0.3 & - & 1 & $2 / 6$ & 33 & $1 / 6$ & 17 & $6 / 6$ & 100 \\
\hline & 30 & 3.1 & 0.8 & - & 1 & $4 / 4$ & 100 & $4 / 4$ & 100 & $2 / 4$ & 50 \\
\hline & 30 & 3.1 & 0.3 & 3 & 1 & $1 / 6$ & 17 & $0 / 6$ & 0 & $6 / 6$ & 100 \\
\hline \multirow[t]{3}{*}{ Postponed } & 30 & 3.1 & 0.3 & - & 10 & $4 / 6$ & 67 & $3 / 6$ & 50 & $2 / 6$ & 33 \\
\hline & 30 & 3.1 & 0.3 & 3 & 10 & $6 / 6$ & 100 & $6 / 6$ & 100 & $5 / 6$ & 83 \\
\hline & 30 & 3.1 & - & 3 & 10 & $6 / 7$ & 86 & $5 / 7$ & 71 & $7 / 7$ & 100 \\
\hline
\end{tabular}

The left column refers to the corresponding results section. Time and dose of treatments applied, occurrence of seizures and convulsions, and survival rate are shown from left to right 
below the right collarbone and between the second and third rib (Lead II configuration) and also fixed to the plug. The plug and the electrodes were fixed to the skull with dental cement.

Acquisition and analysis of EEG and respiration

Before and after poisoning, the animals were placed in a whole-body plethysmograph (Buxco sytems XA, USA) cage to monitor their respiration characteristics. Among other parameters, P-enhanced (Penh), an arbitrary value for bronchoconstriction, and respiratory minute volume were calculated from the signal using IOX software (EMKA technologies, France).

EEG signals were obtained using the PhysioTel telemetry system from Data Sciences Inc. (DSI) using the ML211-EET-F40 transmitter. The transmitter was attached to the plug fixed on the guinea pig's skull. A receiver board measured the signal from the transmitter, which was consolidated and stored on an IBM-compatible personal computer via a Data Exchange matrix at 100-Hz sampling frequency. By visual inspection of the EEG, the starting and ending of seizures, defined as amplitudes increasing three times over baseline, were scored. Additionally, FFT analysis using 10-s epochs was performed to calculate the total power in the spectrum, thereby serving as a semiquantitative measure of seizure activity. Animals were awake during the measurement.

\section{Enzyme activity}

The brain parts were homogenized (900 rpm, 10\% w/v homogenate) in ice-cold TENT buffer, which consisted of $50 \mathrm{mM}$ Tris, $5 \mathrm{mM}$ EDTA, $1 \mathrm{M} \mathrm{NaCl}$ and $1 \% \mathrm{v} / \mathrm{v}$ Triton $\mathrm{X}-100, \mathrm{pH}$ 7.4. The homogenates were centrifuged at $12,000 \mathrm{~g}$ in an Eppendorf centrifuge at $4^{\circ} \mathrm{C}$, and supernatants were immediately frozen in liquid nitrogen and stored at $-20^{\circ} \mathrm{C}$ until analysis of enzyme activity. Blood samples drawn from the ear vein were diluted 10 times in $1 \%$ saponin in MQ, frozen in liquid nitrogen and stored at $-20^{\circ} \mathrm{C}$ until analysis.

Tissue supernatants were analysed for AChE activity using the method described by Ellman et al. (1961), modified for analysis in a 96-well plate reader. Shortly, samples were diluted in $0.8 \mathrm{mM}$ DTNB $\left(5,5^{\prime}\right.$-dithio-bis(2-nitrobenzoic acid)). To $100 \mu \mathrm{l}$ of diluted sample, $100 \mu \mathrm{l}$ of $0.8 \mathrm{mM} \beta$-methylacetylthiocholine iodide was added, in quadruple. For blood samples, $0.8 \mathrm{mM}$ of butyrylthiocholine (BuSChI) was added to separate portions of $100 \mu \mathrm{l}$. The delta OD per min at $415 \mathrm{~nm}$ at ambient temperature served as measurement for ChE activity.

Guinea pig AChE does not react with BuSChI, rendering the BuChE activity determined an appropriate representation of BuChE activity. Brain samples showed no reactivity towards BuSChI. However, AChE activity in blood had to be corrected for cross-reactivity of $\beta$-methylacetylthiocholine with BuChE. The maximum velocity turnover of $\beta$-methylacetylthiocholine by $\mathrm{BuChE}$ was $47 \%$ of that of BuSChI, calculated from separate experiments in which isolated guinea pig $\mathrm{AChE}$ and plasma $\mathrm{BuChE}$ were incubated with both substrates. Therefore, $47 \%$ of the extinction measured with BuSChI as substrate was subtracted from the extinction measured with $\beta$-methylacetylthiocholine, which reacts at a similar rate with $\mathrm{AChE}$ and BuChE. A similar adaptation has been described by Bosgra et al. (2009). Enzyme activity in the tissue supernatants was normalized versus the average enzyme activity of six control animals. AChE and BuChE activities in blood were normalized versus the baseline sample.

Data presentation and statistical analysis

All data were analysed using one-way ANOVA or MANOVA followed by Dunnett's or Tukey's post hoc test using soman or saline as control animals using SPSS statistical software. Results were considered significant for $P<0.05$.

For determination of continuous relationships between blood AChE activity and occurrence of clinical signs, logistic regression analysis was performed. AChE activity of similarly treated animals was coupled to presence of a sign (1) or absence of sign (0). To analyse the effects of soman, animals injected with soman only were included in the analysis $(n=18)$. To analyse the effect of separate treatments, animals were grouped into soman-poisoned animals treated with obidoxime alone, physostigmine alone, atropine alone or the combinations thereof administered at $1 \mathrm{~min}$ after poisoning. Using logistic regression analysis, probability for each level of AChE activity was calculated.

\section{Results}

Soman-poisoned guinea pig model

In the first set of experiments, various soman doses (30, 37 and $44 \mu \mathrm{g} / \mathrm{kg}$ ) were tested for their induction of clinical signs and effects on physiology and biochemistry. A dosedependent effect on survival was found during the 90-min experimental period (See Fig. 2; Table 1). Apart from survival rate, no differences regarding the appearance of other clinical signs were found between the different soman doses, albeit that the onset times of clinical signs, if present, were significantly shorter after poisoning with $44 \mu \mathrm{g} / \mathrm{kg}$ of soman (s.c.) compared to the lower doses (Fig. 2). 


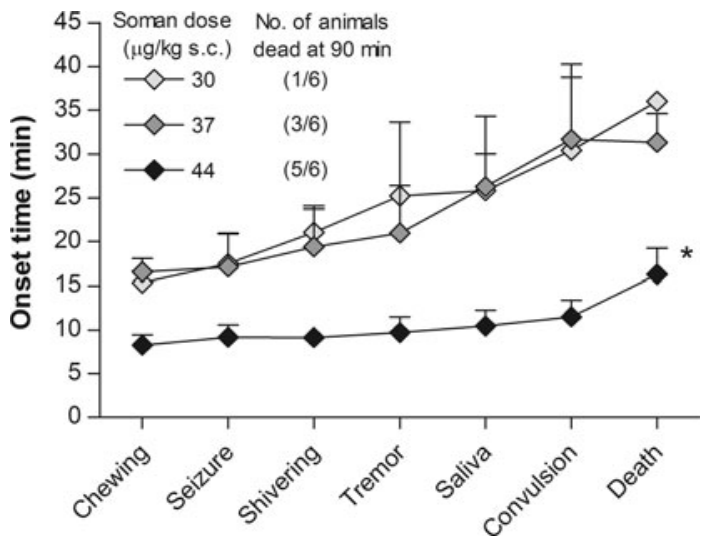

Fig. 2 Average onset times of clinical signs after different doses of soman. Results are presented as means \pm SEM. Onset times of clinical signs in animals poisoned with $44 \mu \mathrm{g} / \mathrm{kg}$ soman were significantly shorter than in animals poisoned with 30 or $37 \mu \mathrm{g} / \mathrm{kg}$ (one-way ANOVA, within factor signs and between factor dose, $P<0.05$ followed by Tukey's post hoc test, $\left.{ }^{*}, P<0.001\right)$

Cholinesterase activity in different brain regions $(\mathrm{AChE})$ at $90 \mathrm{~min}$ and in blood (AChE and BuChE) at 10 min after poisoning was dose dependently inhibited by soman (MANOVA, $P<0.001$ ). However, there were no significant differences in inhibition between the different doses [Tukey HSD post hoc test $P>0.05$ (Table 2)].

Regardless the dose, all animals poisoned with soman developed seizures within 5-30 min, albeit that animals poisoned with the highest dose tended to develop fullblown seizures more rapidly (Fig. 3a). Seizure development is characterized by an increase in total power of the fast Fourier transformation of the spectrum of the EEG signal (FFT) compared to seizure-free EEG. In contrast to animals poisoned with 30 or $37 \mu \mathrm{g} / \mathrm{kg}$, which merely survived the 90-min observation period, animals poisoned

Table 2 Relative residual ChE activity in blood at $10 \mathrm{~min}$ and in different brain areas at 90 min post-poisoning

\begin{tabular}{|c|c|c|c|}
\hline \multirow{2}{*}{$\begin{array}{l}\% \mathrm{ChE} \text { activity in } \\
\text { blood and brain parts }\end{array}$} & \multicolumn{3}{|c|}{ Soman dose $(\mu \mathrm{g} / \mathrm{kg}$ s.c. $)$} \\
\hline & 30 & 37 & 44 \\
\hline \multicolumn{4}{|l|}{ Blood } \\
\hline AChE & $0.9 \pm 1.2$ & $3.9 \pm 2.8$ & $11.0 \pm 16.1$ \\
\hline BuChe & $3.5 \pm 0.6$ & $8.4 \pm 1.5$ & $28.6 \pm 7.4$ \\
\hline \multicolumn{4}{|l|}{ Brain } \\
\hline Medulla oblongata & $23.9 \pm 3.3$ & $19.7 \pm 6.0$ & $11.2 \pm 5.2$ \\
\hline Striatum & $13.1 \pm 2.6$ & $12.8 \pm 5.7$ & $9.1 \pm 1.5$ \\
\hline Hippocampus & $10.0 \pm 3.4$ & $4.7 \pm 2.4$ & $2.0 \pm 1.1$ \\
\hline
\end{tabular}

High levels of inhibition of AChE and BuChE are achieved in blood and in brain. Enzyme activity was significantly lower than that of unpoisoned control animals (100\% activity), and no difference between soman doses was found (MANOVA followed by Tukey HSD post hoc test) with $44 \mu \mathrm{g} / \mathrm{kg}$ died rapidly after onset of seizures. In surviving animals, seizures continued with similar intensity over the entire 90-min observation period (Fig. 3a).

Additionally, heart rate and respiratory parameters were measured as main vital parameters. There were no obvious and consistent effects of soman on heart rate (not shown), whereas effects on respiration parameters were clearly present. After soman poisoning, a clear and significant increase in respiratory minute volume (RMV) compared to control animals was present (Fig. 3b). Soman poisoning also resulted in an increase in bronchoconstriction, which was, however, not significant (not shown). For these physiological parameters, no dose-response effect of soman was observed.

\section{Efficacy of conventional therapy}

In animals poisoned with $30 \mu \mathrm{g} / \mathrm{kg}$ s.c. soman, components of the treatment currently in use were tested. The effects of different doses and combinations of obidoxime $(3.1,9$ and $18 \mathrm{mg} / \mathrm{kg})$ and atropine $(0.03$ and $3 \mathrm{mg} / \mathrm{kg})$ were tested. None of the obidoxime doses tested induced a significant reactivation of $\mathrm{AChE}$ or $\mathrm{BuChE}$ in blood at any time point (not shown). Only a dose of $3.1 \mathrm{mg} / \mathrm{kg}$ obidoxime had induced a significant increase in AChE activity in the medulla oblongata at $90 \mathrm{~min}$ after poisoning (Fig. 4a).

Analysis of the occurrence of clinical signs (Table 1) showed that only the lowest dose of obidoxime $(3.1 \mathrm{mg} / \mathrm{kg})$ prevented the development of convulsions in $67 \%$ of animals. Although convulsions were prevented in a high number of animals, seizures were prevented in a low number of animals (33\%). Addition of either 0.03 or $3 \mathrm{mg} / \mathrm{kg}$ atropine to the treatment did not further improve this. None of these treatments had a significant effect on the onset time of clinical signs, although the increase in EEG power over time (Fig. 5a) showed some delay in seizure onset. Only the highest dose of atropine ( $3 \mathrm{mg} / \mathrm{kg}$ ), either with or without obidoxime, prevented the development of salivation, in contrast to the autoinjector-equivalent dose of $0.03 \mathrm{mg} / \mathrm{kg}$.

Regarding the respiration parameters, the lowest dose of obidoxime $(3.1 \mathrm{mg} / \mathrm{kg})$ showed a slight and statistically insignificant improvement of respiratory minute volume (Fig. 6a). Addition of atropine to the treatment with obidoxime showed some positive but insignificant effect on RMV (Fig. 6a), whereas atropine alone did not show any improvement at all. In contrast to no treatment, treatment with the highest dose of obidoxime induced a clear effect on heart rate. A pressor effect directly after injection of obidoxime (i.m.) was followed by a depressant effect at $\sim 45 \mathrm{~min}$ after injection (not shown). 
Fig. 3 a Effects of different doses of soman on total power in EEG. b respiratory minute volume (RMV). Results are presented as mean \pm SEM. No significant differences were observed between the different soman doses
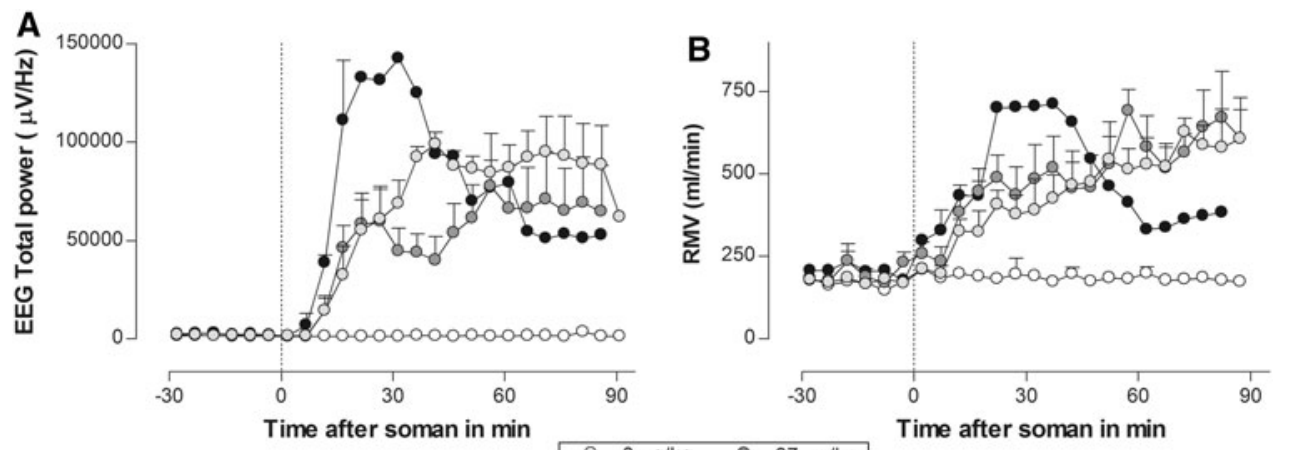

$-0-0 \mu \mathrm{g} / \mathrm{kg} \longrightarrow 37 \mu \mathrm{g} / \mathrm{kg}$
$-0-30 \mu \mathrm{g} / \mathrm{kg} \longrightarrow-44 \mu \mathrm{g} / \mathrm{kg}$
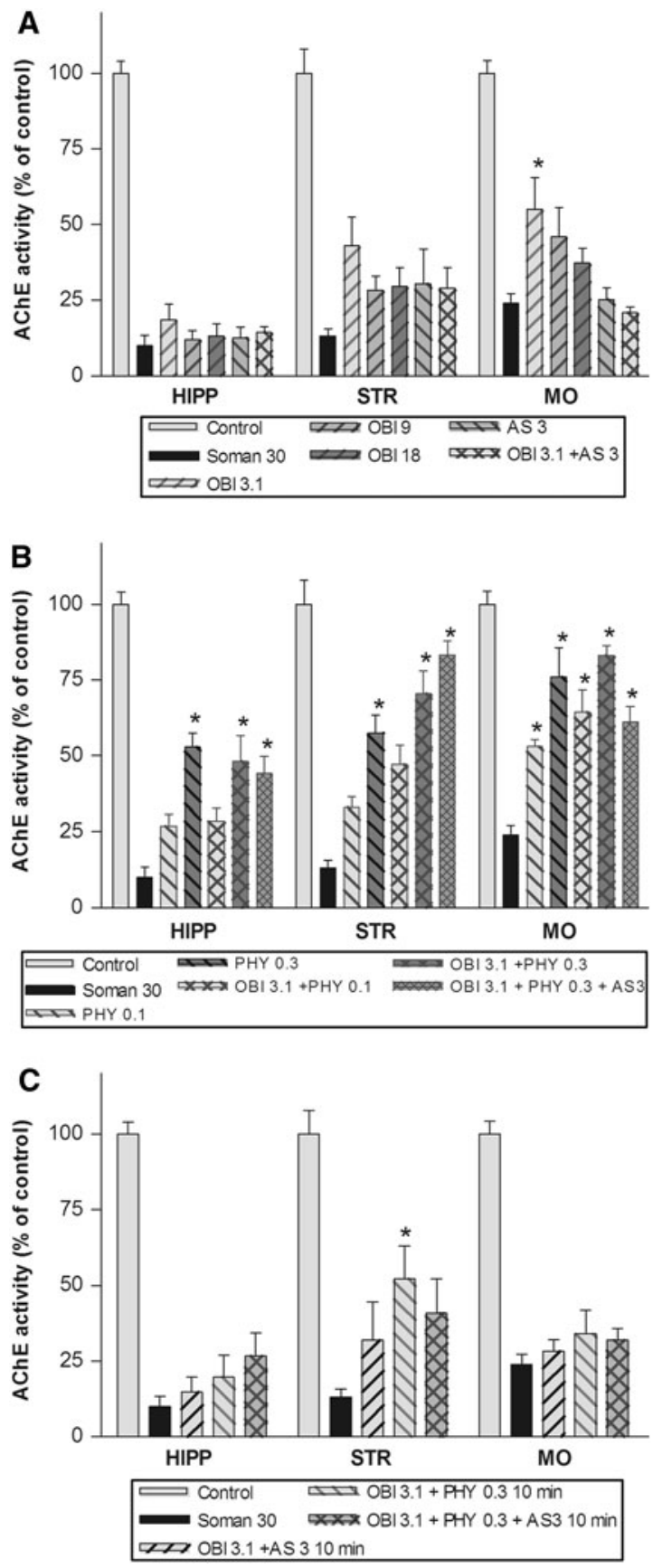

4 Fig. 4 a AChE activity in hippocampus, striatum and medulla oblongata (HIPP, STR and MO) 90 min after poisoning with soman and subsequent treatment. The effect of obidoxime (3.1, 9 and $18 \mathrm{mg} / \mathrm{kg})$ and atropine $(3 \mathrm{mg} / \mathrm{kg}) 1 \mathrm{~min}$ after poisoning with $30 \mu \mathrm{g} / \mathrm{kg}$ soman. b Efficacy of addition of physostigmine $(0.1$ and $0.8 \mathrm{mg} / \mathrm{kg}$ ). $\mathbf{c}$ the effects of treatments postponed to $10 \mathrm{~min}$. Results are presented as mean \pm SEM and analysed by MANOVA followed by Tukey's HSD post hoc test. *indicates significant $(P<0.05)$ compared to soman alone

To investigate the extent of efficacy against a higher dose of soman, the optimal obidoxime treatment $(3.1 \mathrm{mg} / \mathrm{kg})$ combined with atropine sulphate was tested against $44 \mu \mathrm{g} / \mathrm{kg}$ of soman s.c. Although this treatment promoted survival, none of the other physiological effects, such as convulsions or seizure development and respiratory effects, were prevented (data not shown).

\section{Efficacy of physostigmine}

The therapeutic efficacy of physostigmine as immediate treatment in case of organophosphate poisoning was tested in three different doses: $0.1 ; 0.3$ and $0.8 \mathrm{mg} / \mathrm{kg}$ i.m., administered at $1 \mathrm{~min}$ after soman poisoning. In particular, the middle dose $(0.3 \mathrm{mg} / \mathrm{kg})$ showed a major improvement on most parameters. Only a small proportion of the animals treated with this dose of physostigmine showed the development of seizures and convulsions (2/6 and 1/6, respectively, see Table 1). Additionally, soman-induced effects on respiration were prevented in animals treated with $0.3 \mathrm{mg} / \mathrm{kg}$ of physostigmine, but not by the other doses (Fig. 6b). This was accompanied by high residual AChE activity in blood and brain regions (Fig. 4b). Treatment with the highest dose of physostigmine, $0.8 \mathrm{mg} / \mathrm{kg}$, accelerated the development of clinical signs. In addition to an increase in RMV, these animals showed high levels of bronchoconstriction. In contrast to untreated animals, these animals died within 30-45 min after poisoning, in spite of residual AChE activity similar to that of animals treated with $0.3 \mathrm{mg} / \mathrm{kg}$. The lowest dose of physostigmine, $0.1 \mathrm{mg} / \mathrm{kg}$, prevented the development of convulsions in 


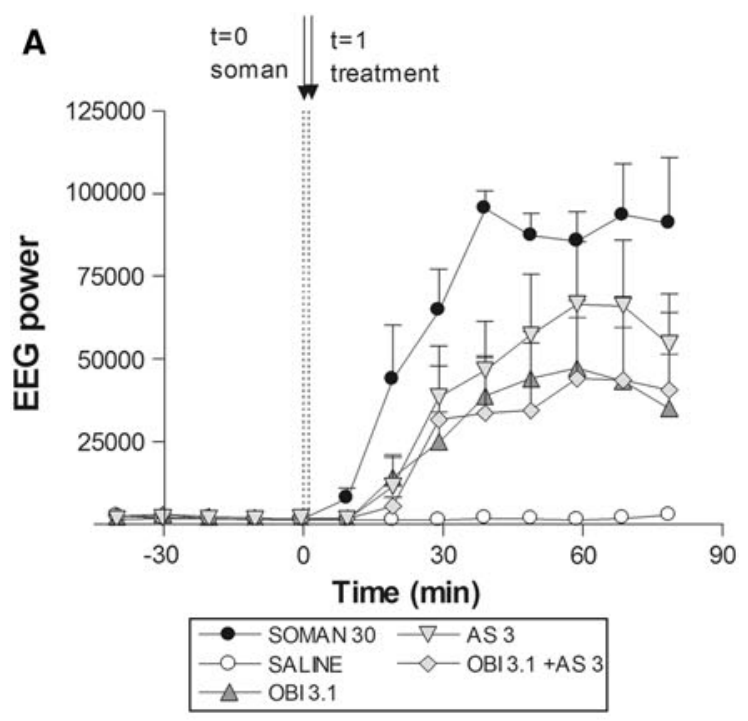

B
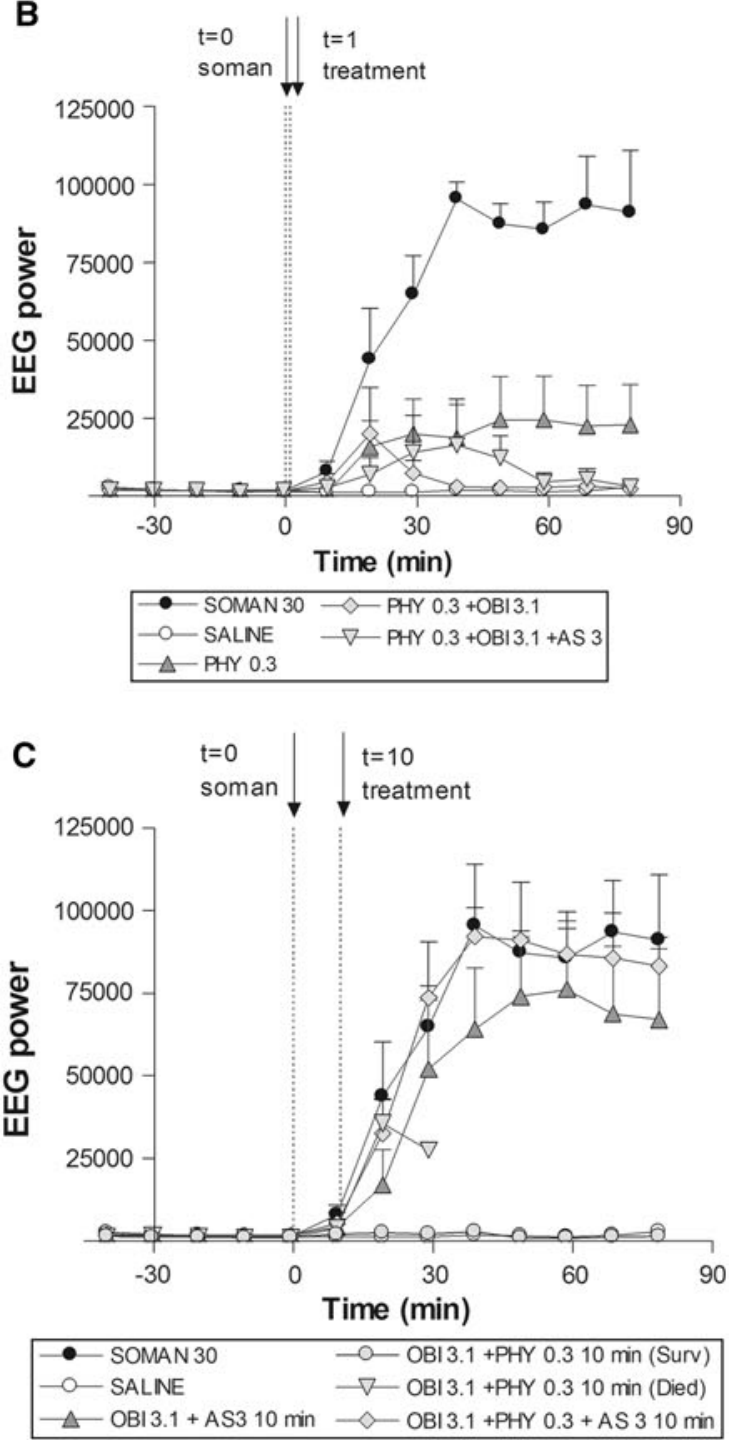

Fig. 5 a Treatment effect on total power in EEG before and after soman poisoning. Results are presented as 10 -min averages $\pm \mathrm{SEM}$. The effect of obidoxime $(3.1 \mathrm{mg} / \mathrm{kg})$ and atropine $(3 \mathrm{mg} / \mathrm{kg})$ administered at $1 \mathrm{~min}$ after soman poisoning. $\mathbf{b}$ The effect of physostigmine $(0.3 \mathrm{mg} / \mathrm{kg})$ alone or as an addition to obidoxime and/or atropine. c The effect of similar treatments administered at $10 \mathrm{~min}$ after poisoning

five out of six animals, but not seizures. Residual AChE activity in the brains of these animals showed to be lower than in the animals treated with other physostigmine doses (Fig. 4b). In particular, AChE activity showed to be preserved by physostigmine, and no residual BuChE activity was detected in blood.

When different physostigmine doses were combined with the most efficacious dose of obidoxime $(3.1 \mathrm{mg} / \mathrm{kg})$, again the dose of $0.3 \mathrm{mg} / \mathrm{kg}$ physostigmine showed the highest efficacy. Seizure development was prevented in most animals, and if present, they only lasted for a maximum of $15 \mathrm{~min}$ (Fig. 5b). The highest dose of physostigmine $(0.8 \mathrm{mg} / \mathrm{kg})$ combined with obidoxime also aggravated signs, including survival (3/6 animals died within $90 \mathrm{~min}$ ), but the effects were less deleterious compared to physostigmine $(0.8 \mathrm{mg} / \mathrm{kg})$ treatment alone. Physostigmine $0.1 \mathrm{mg} / \mathrm{kg}$ combined with obidoxime showed some efficacy on residual enzyme activity and accordingly on convulsions, seizures and respiration. In contrast to physostigmine alone, seizures were prevented in two out of six animals. Residual enzyme activity was not different between animals treated with physostigmine alone and physostigmine combined with obidoxime (Fig. 4b).

The addition of atropine $(3 \mathrm{mg} / \mathrm{kg})$ to the most efficacious physostigmine/obidoxime combination showed no improvements compared to the combination without atropine (Fig. 5b). One animal developed seizures for a short period of $\sim 30 \mathrm{~min}$, which was similar to the result shown in the group of animals treated with physostigmine and obidoxime. In all animals, RMV increase and bronchoconstriction were prevented, but to a similar extent as in animals treated with the combination of physostigmine and obidoxime (Fig. 6b).

\section{Efficacy of postponed treatment}

As in practice, treatment will be postponed until overt signs are present; we also administered the most efficacious combination of obidoxime $(3.1 \mathrm{mg} / \mathrm{kg})$ and atropine (3 $\mathrm{mg} / \mathrm{kg}$ ) at $10 \mathrm{~min}$ after poisoning with $30 \mu \mathrm{g} / \mathrm{kg}$ soman, when toxic signs were already visible. These experiments showed that in that case, the therapeutic efficacy of the combination nearly completely lost its effectiveness on all 

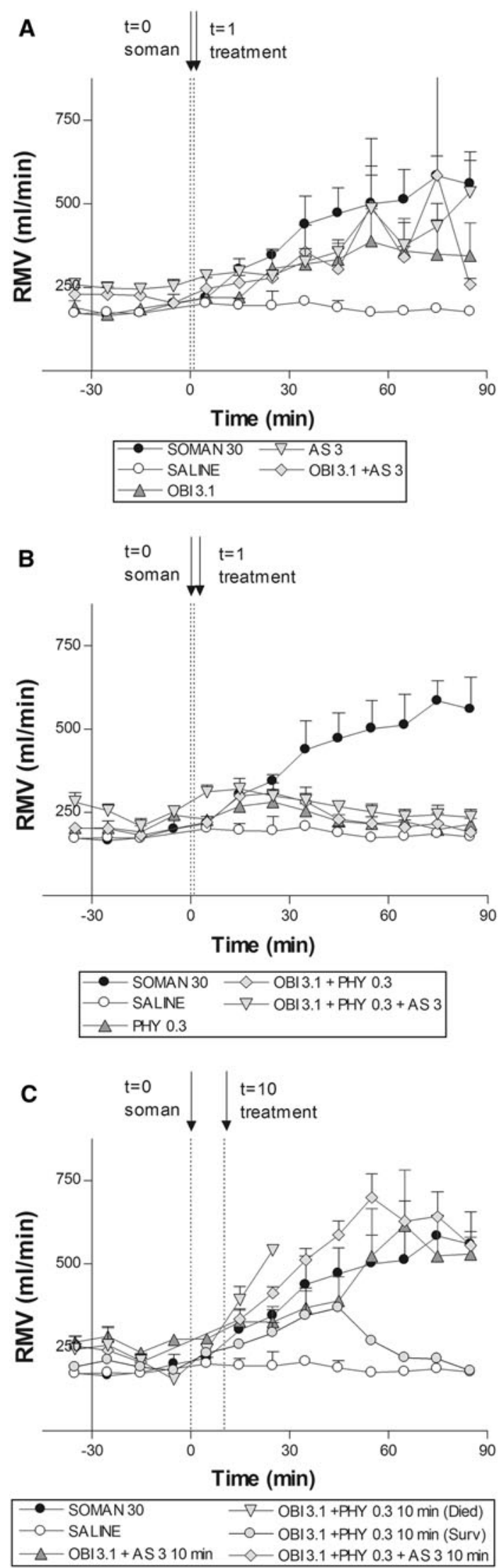

Fig. 6 a Treatment effect on respiratory minute volume (RMV) before and after soman poisoning. Results are presented as 10-min averages \pm SEM. The effect of obidoxime $(3.1 \mathrm{mg} / \mathrm{kg})$ and atropine ( $3 \mathrm{mg} / \mathrm{kg}$ ) administered at $1 \mathrm{~min}$ after soman poisoning. b The effect of physostigmine $(0.3 \mathrm{mg} / \mathrm{kg})$ alone or as an addition to obidoxime and/or atropine. c The effect of similar treatments administered at 10 min after poisoning

parameters. Salivation was prevented in all animals, but RMV increase (Fig. 6c) and seizure development were not affected (Fig. 5c). In two out of six animals, convulsions were prevented (Table 1), whereas the onset time of convulsions in the remaining animals tended to be later $(P>0.05)$.

The combination physostigmine $(0.3 \mathrm{mg} / \mathrm{kg})$ and obidoxime $(3.1 \mathrm{mg} / \mathrm{kg})$, showing outstanding efficacy when administered at 1 min after poisoning, showed full efficacy in two out of six animals, but in four out of six animals, lethality was accelerated when the combination was administered at $10 \mathrm{~min}$.

The full combination of obidoxime, atropine and physostigmine also completely lost efficacy, in that seizure development (Fig. 5c) and increase in RMV (Fig. 6c) were similar to that of untreated animals. Accordingly, no improvements in residual AChE activity were found in the different brain regions, except the physostigmine-obidoxime combination, which showed some improvement in the striatum (Fig. 4c).

\section{Discussion}

In the present experiments, a guinea pig model was developed to study soman poisoning and therapeutic efficacy of immediate and postponed treatment. The guinea pig soman model doses showed to be suitable for investigating different levels of therapeutic efficacy. First of all, the lowest dose, $30 \mu \mathrm{g} / \mathrm{kg}$, showed to be most suitable to investigate therapeutic effects on physiology, whereas the highest dose allowed the assessment of efficacy regarding survival. Seizure development, accompanied by increased RMV and to a lesser extent to an increase of bronchoconstriction, was present in all animals at all soman doses. The increase in RMV was primarily mediated by an increase in tidal volume, rather than by increased respiratory frequency. Although this finding was unexpected, a pronounced involvement of, in particular, the M1 and M3 mAChRs in the control of respiration might explain the increased tidal volume and RMV observed after soman exposure (Boudinot et al. 2008). In addition, bronchorrhea and bronchoconstriction mediate lower $\mathrm{pO}_{2}$ levels in blood, thereby stimulating chemoreceptors in the respiratory centres (Wiener and Hoffman 2004). Bradycardia expected 
to be present due to cholinergic overstimulation was absent, probably due to a sympathetic response. In contrast with AChE activity in blood at $10 \mathrm{~min}$ post-poisoning, a soman dose-response effect on AChE activity was found in all brain regions analysed, resulting in 80-90\% inhibition at $90 \mathrm{~min}$ post-poisoning. Similar results were reported by Shih et al. (2005), who investigated the differential inhibition of various nerve agent types in several organs.

AChE activity in blood mainly serves as biomarker for exposure and not for toxicity (Lotti 1995). It was shown previously that AChE activity in blood is a bad predictor for cholinergic clinical signs due to acute OP poisoning (Bueters et al. 2003). Logistic regression analysis of the present results, using lower doses of OP compared to that study, revealed the inhibition of $\mathrm{AChE}$ in blood to be a good predictor for the probability of chewing, shivering, seizures, convulsions and tremor, but not for respiratory distress and death (Fig. 7a). This shows that seizures are accompanied and not necessarily preceded by mild clinical signs. It also shows that poisoning with lower doses does not ameliorate the chance of development of severe clinical signs. The most severe sign well predicted by blood AChE
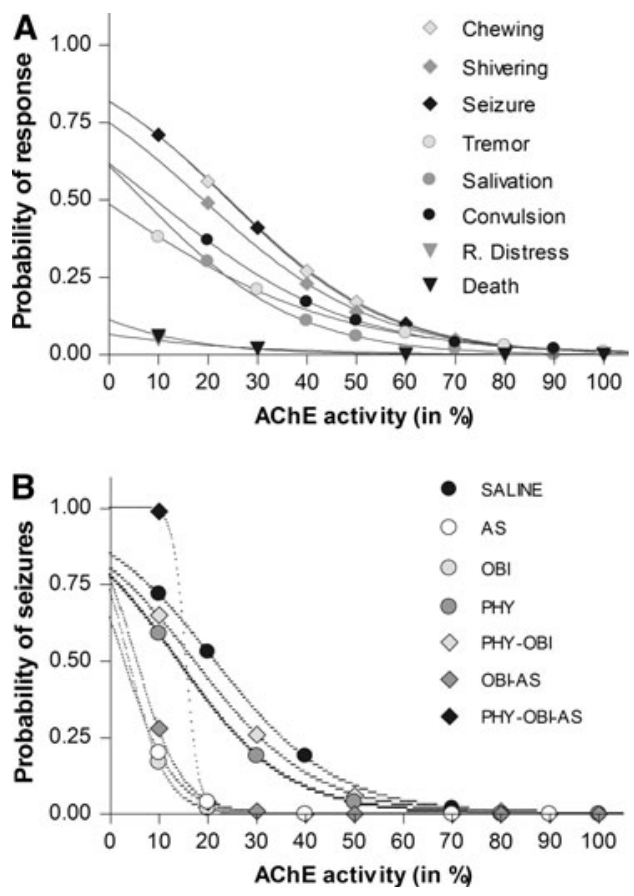

Fig. 7 Continuous relationships of the occurrence of soman-induced signs obtained with logistic regression analysis. a The relationship between AChE activity in blood and clinical signs of animals poisoned with three doses of soman but no treatment $(n=18)$. $\mathbf{b}$ The relationship between the probability of seizures and the residual AChE of animals poisoned with $30 \mu \mathrm{g} / \mathrm{kg}$ soman treated at $1 \mathrm{~min}$ post-poisoning with single drugs or their combinations $(n=6-18$ per treatment) activity was seizure development, mostly held responsible for adverse effects at the long term. The toxicokinetics of soman are not linear, higher doses lead to relatively much higher AUC and less rapid clearance than following lower doses (Van der Schans et al. 2008). This implicates that at higher doses, binding sites will more rapidly be saturated, leading to a more rapid development of clinical signs. In contrast, at lower doses, as used in the present study, clearance is higher, leading to a more gradual and slower pattern of poisoning, and AChE activity in blood might more accurately reflect the levels of neuronal AChE activity, resulting in a better prediction of development of clinical signs.

These findings underscore that protection of AChE activity is a primary target for treatment in case of OP exposure. Only at the lowest dose of $3.1 \mathrm{mg} / \mathrm{kg}$ and not at both higher doses of 9 and $18 \mathrm{mg} / \mathrm{kg}$, obidoxime showed significant reactivation in the medulla oblongata, but not in blood or other brain parts. The efficacy of the lowest dose of obidoxime on the development of convulsions, seizures and respiratory deterioration might be explained by the higher level of AChE activity found in the medulla oblongata. It might be speculated that some reactivation of soman-inhibited AChE occurs in the first minutes after the administration of obidoxime, before our first measuring point and ageing of soman-inhibited AChE. The higher number of binding sites for soman in blood probably reduced the soman load that entered the brain, causing less inhibition in the medulla oblongata. The decline of therapeutic efficacy at higher doses of obidoxime might be ascribed to the inhibitory actions that phosphonylated obidoxime exerts on AChE (Harvey et al. 1986; van Helden et al. 1994). The slight delay of complete inhibition of AChE in the blood and probably also in the brain by obidoxime might explain its therapeutic efficacy, as only little amounts of active $\mathrm{AChE}$ in the brain are sufficient to improve the aforementioned parameters (Bueters et al. 2003). In addition, suspected direct pharmacological actions of obidoxime might facilitate adaptive processes (van Helden et al. 1994, 1996). Obidoxime is capable of increasing ACh release two- to threefold in the absence of AChE inhibitors, which can contribute to accelerated adaptation of cholinergic synapses to increased ACh levels and thereby to protection against the toxic load of soman (Oydvin et al. 2005). Second, obidoxime is known to allosterically modulate the $\mathrm{mAChR} 2$ receptor (Gnagey and Ellis 1996; Grossmuller et al. 2006; Kloog et al. 1985), which is involved in cholinergic feedback mechanisms (Segal 1989).

Addition of atropine sulphate to obidoxime in exactly one autoinjector equivalent $(0.03 \mathrm{mg} / \mathrm{kg})$ had no added value at all. A higher dose of atropine, $3 \mathrm{mg} / \mathrm{kg}$, a dose similar to that often used in OP-research, revealed some protection, in 
particular against extensive salivation and convulsions, and to a lesser extent to seizure development and respiration. In contrast to low autoinjector-equivalent doses, only such higher doses showed to be an effective support for anticonvulsant treatments (Shih et al. 2007). In addition, we show that the combined treatment with atropine and obidoxime enhances survival in case of poisoning with $44 \mu \mathrm{g} / \mathrm{kg}$ of soman. Other researchers have showed higher efficacy using relatively high doses of the much more potent mAChR antagonist scopolamine. It might therefore be advisable to replace atropine by scopolamine, although extrapolation of the dose from animal research to the human situation remains difficult (Wetherell et al. 2007).

Physostigmine was previously proposed as alternative immediate treatment against 5 LD50 of soman (Wetherell et al. 2006, 2007). In case of poisoning with soman, physostigmine, at a similar dose as used in our study, was rather effective, and its efficacy increased when high doses of HI-6 were used, which was ascribed to the competition with incoming soman for binding sites (Wetherell et al. 2007). In the present study, the therapeutic window of physostigmine appeared to be very small. We showed that $0.1 \mathrm{mg} / \mathrm{kg}$ physostigmine provided some protection when administered at $1 \mathrm{~min}$ after poisoning and that $0.3 \mathrm{mg} / \mathrm{kg}$ showed to be most effective, but $0.8 \mathrm{mg} / \mathrm{kg}$ appeared to aggravate clinical signs and to diminish survival. Residual AChE activity was measured using a modified Ellman reaction, revealing the AChE fraction that was inhibited by physostigmine in vivo. During sample preparation, physostigmine-inhibited AChE was likely to fully decarbamylate because of its short half-life of approximately $32 \mathrm{~min}$ in vitro (Wetherell and French 1991). Therefore, the inhibited fraction most likely reflects the portion of AChE inhibited by soman, because without treatment, the dose of soman used was sufficient to fully inhibit AChE activity in blood. Measurements of residual AChE activity showed that the lowest dose $(0.1 \mathrm{mg} / \mathrm{kg})$ provided the lowest protection of AChE by physostigmine, whereas the higher doses 0.3 and $0.8 \mathrm{mg} / \mathrm{kg}$ inhibited a similar fraction of $\mathrm{AChE}$ ( $\sim 50 \%$ of activity). These findings indicate that the small therapeutic window is probably due to the carbamylation rate of physostigmine, being too low at a dose of $0.1 \mathrm{mg} / \mathrm{kg}$, whereas the carbamylation rate of physostigmine exceeded decarbamylation at a dose of $0.8 \mathrm{mg} / \mathrm{kg}$. Only at the middle dose tested, $0.3 \mathrm{mg} / \mathrm{kg}$, carbamylation and decarbamylation were balanced leading to protection of sufficient amounts of AChE to exert protection. Although the measurements of residual AChE activity in animals receiving postponed treatment with physostigmine did not reveal a significant decline or protection of AChE activity, our results show that postponed treatment with a dose of
$0.3 \mathrm{mg} / \mathrm{kg}$ physostigmine clearly led to a lower survival rate and loss of therapeutic efficacy in these animals. These results indicate that postponed treatment with physostigmine induces an additional increase in AChE inhibition in blood and brain to that already brought about by soman. This implies that administration of physostigmine can only be protective when a considerable fraction of AChE is not yet occupied by soman, which was accomplished by the 1-min treatment.

To compare all treatments for their mechanism of action, logistic regression analysis was performed to estimate the probability of seizure development at certain levels of blood AChE activity in animals receiving different treatments after soman poisoning $(30 \mu \mathrm{g} / \mathrm{kg})$ (Fig. 7b). This analysis showed that when atropine or obidoxime or their combination was used as a treatment, the seizure probability dramatically decreased at similar AChE activity, confirming the mechanism of atropine and obidoxime in this study to be largely independent from AChE reactivation. However, when physostigmine treatment without atropine was employed, seizure probability at similar AChE activity remained comparable to that in untreated animals. This indicates that the efficacy of physostigmine is probably only due to its ability to prevent soman from binding to $\mathrm{AChE}$, thereby reserving a decarbamylating pool of AChE while the OP is degraded, and is not due to suspected effects on nicotinic receptors (Harris et al. 1990).

In conclusion, the present results show that the combination atropine and obidoxime is hardly effective against soman poisoning, even at a fairly low toxic load as used in the present study. However, for nerve agents that are more prone to reactivation than soman, this regimen is expected to show higher efficacy. Although physostigmine significantly improved therapeutic outcomes, there might be some drawbacks to adding physostigmine to the current autoinjector components. In practice, treatment will only be administered at appearance of toxic signs, indicating inhibition of the major fraction AChE by nerve agent. In particular, at high levels of nerve agent poisoning, carbamates will fully inhibit the small remaining pool of AChE, thereby further pushing cholinergic overstimulation and worsen the clinical condition. Treatment of OP poisoning with a carbamate, such as physostigmine, should therefore carefully be re-evaluated.

Acknowledgments Funding information This work was supported by the Dutch Ministry of Defence.

Open Access This article is distributed under the terms of the Creative Commons Attribution Noncommercial License which permits any noncommercial use, distribution, and reproduction in any medium, provided the original author(s) and source are credited. 


\section{References}

Aas P (2003) Future considerations for the medical management of nerve-agent intoxication. Prehosp Disaster Med 3:208-216

Albuquerque EX, Pereira EF, Aracava Y, Fawcett WP, Oliveira M, Randall WR, Hamilton TA, Kan RK, Romano JA Jr, Adler M (2006) Effective countermeasure against poisoning by organophosphorus insecticides and nerve agents. Proc Natl Acad Sci U S A 35:13220-13225

Berman HA, Decker MM (1986) Kinetic, equilibrium, and spectroscopic studies on dealkylation ("aging") of alkyl organophosphonyl acetylcholinesterase. Electrostatic control of enzyme topography. J Biol Chem 23:10646-10652

Bosgra S, van Eijkeren JC, van der Schans MJ, Langenberg JP, Slob W (2009) Toxicodynamic analysis of the combined cholinesterase inhibition by paraoxon and methamidophos in human whole blood. Toxicol Appl Pharmacol 1:9-15

Boudinot E, Champagnat J, Foutz AS (2008) M(1)/M(3) and M(2)/ M(4) muscarinic receptor double-knockout mice present distinct respiratory phenotypes. Respir Physiol Neurobiol 1:54-61

Bueters TJ, Joosen MJ, van Helden HP, IJzerman AP, Danhof M (2003) Adenosine A1 receptor agonist N6-cyclopentyladenosine affects the inactivation of acetylcholinesterase in blood and brain by sarin. J Pharmacol Exp Ther 3:1307-1313

Dirnhuber P, French MC, Green DM, Leadbeater L, Stratton JA (1979) The protection of primates against soman poisoning by pretreatment with pyridostigmine. J Pharm Pharmacol 5:295-299

Gnagey A, Ellis J (1996) Allosteric regulation of the binding of $[3 \mathrm{H}]$ acetylcholine to $\mathrm{m} 2$ muscarinic receptors. Biochem Pharmacol 11:1767-1775

Gordon JJ, Leadbeater L (1977) The prophylactic use of 1-methyl, 2-hydroxyiminomethylpyridinium methanesulfonate (P2S) in the treatment of organophosphate poisoning. Toxicol Appl Pharmacol 1:109-114

Gordon JJ, Leadbeater L, Maidment MP (1978) The protection of animals against organophosphate poisoning by pretreatment with a carbamate. Toxicol Appl Pharmacol 1:207-216

Grossmuller M, Antony J, Trankle C, Holzgrabe U, Mohr K (2006) Allosteric site in M2 acetylcholine receptors: evidence for a major conformational change upon binding of an orthosteric agonist instead of an antagonist. Naunyn Schmiedebergs Arch Pharmacol 4:267-276

Harris LW, Anderson DR, Pastelak AM, Vanderpool B (1990) Acetylcholinesterase inhibition by $(+)$ physostigmine and efficacy against lethality induced by soman. Drug Chem Toxicol 2-3:241-248

Harvey B, Scott RP, Sellers DJ, Watts P (1986) In vitro studies on the reactivation by oximes of phosphylated acetylcholinesterase-I. On the reactions of $\mathrm{P} 2 \mathrm{~S}$ with various organophosphates and the properties of the resultant phosphylated oximes. Biochem Pharmacol 5:737-744

Hilmas CJ, Poole MJ, Finneran K, Clark MG, Williams PT (2009) Galantamine is a novel post-exposure therapeutic against lethal VX challenge. Toxicol Appl Pharmacol 240(2):166-173

Joosen MJ, Jousma E, van den Boom TM, Kuijpers WC, Smit AB, Lucassen PJ, van Helden HP (2009) Long-term cognitive deficits accompanied by reduced neurogenesis after soman poisoning. Neurotoxicology 1:72-80

Kloog Y, Galron R, Balderman D, Sokolovsky M (1985) Reversible and irreversible inhibition of rat brain muscarinic receptors is related to different substitutions on bisquaternary pyridinium oximes. Arch Toxicol 1:37-39
Lotti M (1995) Cholinesterase inhibition: complexities in interpretation. Clin Chem 12(Pt 2):1814-1818

Maxwell DM, Brecht KM, Koplovitz I, Sweeney RE (2006) Acetylcholinesterase inhibition: does it explain the toxicity of organophosphorus compounds? Arch Toxicol 11:756-760

Maxwell DM, Koplovitz I, Worek F, Sweeney RE (2008) A structureactivity analysis of the variation in oxime efficacy against nerve agents. Toxicol Appl Pharmacol 2:157-164

McDonough JH Jr, McMonagle J, Copeland T, Zoeffel D, Shih TM (1999) Comparative evaluation of benzodiazepines for control of soman-induced seizures. Arch Toxicol 8-9:473-478

McDonough JH Jr, Zoeffel LD, McMonagle J, Copeland TL, Smith CD, Shih TM (2000) Anticonvulsant treatment of nerve agent seizures: anticholinergics versus diazepam in soman-intoxicated guinea pigs. Epilepsy Res 1:1-14

Oydvin OK, Tanso R, Aas P (2005) Pre-junctional effects of oximes on $[3 \mathrm{H}]$-acetylcholine release in rat hippocampal slices during soman intoxication. Eur J Pharmacol 3:227-234

Raveh L, Brandeis R, Gilat E, Cohen G, Alkalay D, Rabinovitz I, Sonego H, Weissman BA (2003) Anticholinergic and antiglutamatergic agents protect against soman-induced brain damage and cognitive dysfunction. Toxicol Sci 1:108-116

Segal M (1989) Presynaptic cholinergic inhibition in hippocampal cultures. Synapse 4:305-312

Shih TM, McDonough JH Jr (1997) Neurochemical mechanisms in soman-induced seizures. J Appl Toxicol 4:255-264

Shih TM, McDonough JH (2000) Efficacy of biperiden and atropine as anticonvulsant treatment for organophosphorus nerve agent intoxication. Arch Toxicol 3:165-172

Shih TM, Kan RK, McDonough JH (2005) In vivo cholinesterase inhibitory specificity of organophosphorus nerve agents. Chem Biol Interact 293-303

Shih TM, Rowland TC, McDonough JH (2007) Anticonvulsants for nerve agent-induced seizures: the influence of the therapeutic dose of atropine. J Pharmacol Exp Ther 1:154-161

Suzuki T, Morita H, Ono K, Maekawa K, Nagai R, Yazaki Y (1995) Sarin poisoning in Tokyo subway. Lancet 8955:980

Van der Schans MJ, Benschop HP, Whalley CM (2008) Toxicokinetics of nerve agents. 5:97-122

van Helden HP, Bueters TJ (1999) Protective activity of adenosine receptor agonists in the treatment of organophosphate poisoning. Trends Pharmacol Sci 11:438-441

van Helden HP, van der Wiel HJ, Zijlstra JJ, Melchers BP, Busker RW (1994) Comparison of the therapeutic effects and pharmacokinetics of HI-6, HLo-7, HGG-12, HGG-42 and obidoxime following non-reactivatable acetylcholinesterase inhibition in rats. Arch Toxicol 4:224-230

van Helden HP, Busker RW, Melchers BP, Bruijnzeel PL (1996) Pharmacological effects of oximes: how relevant are they? Arch Toxicol 12:779-786

Wetherell JR, French MC (1991) A comparison of the decarbamoylation rates of physostigmine-inhibited plasma and red cell cholinesterases of man with other species. Biochem Pharmacol 3:515-520

Wetherell J, Price M, Mumford H (2006) A novel approach for medical countermeasures to nerve agent poisoning in the guineapig. Neurotoxicology 4:485-491

Wetherell J, Price M, Mumford H, Armstrong S, Scott L (2007) Development of next generation medical countermeasures to nerve agent poisoning. Toxicology 1-3:120-127

Wiener SW, Hoffman RS (2004) Nerve agents: a comprehensive review. J Intensive Care Med 1:22-37 